\title{
Caracterização farmacognóstica da espécie Erythrina falcata Benth., Fabaceae
}

\author{
Emanuel Eustáquio Almeida \\ Universidade do Vale do Sapucaí, Departamento de Ciências Biológicas, Av. Pref. Tuanny Toledo, 470, \\ 37550-000 Pouso Alegre-MG, Brasil.
}

\begin{abstract}
RESUMO: Erythrina falcata Benth., Fabaceae, conhecida popularmente no Brasil pelos nomes de mulungu, sapatinho-de-judeu, corticeira-da-serra, muchoco, é usada pela população como planta medicinal indicada como sedativo, ansiolítico ou para doenças do aparelho respiratório. Seu uso indiscriminado, no entanto, pode trazer consequências graves à saúde, devido à forte presença de alcaloides, particularmente nas sementes e na casca. O presente trabalho tem como objetivo estudos fitoquímicos para identificação dos principais grupos de substâncias existentes na espécie, além de estudos morfológicos e histológicos para diferenciação entre outras espécies do gênero.
\end{abstract}

Unitermos: alcaloides, fitoquímico; morfohistológico.

\begin{abstract}
Pharmacognosy of the specie Erythrina falcata Benth., Fabaceae". Erythrina falcata Benth., Fabaceae, popularly known in Brazil by the mulungu names, shoe-of-jew, corkgive-mountain, muchoco, is used by the population as suitable medicinal plant as sedative and anxiolytic. It is also used against diseases of the breathing apparel. Its indiscriminate use, however, can bring serious consequences to the health, due to strong presence of alkaloids, particularly in the seeds and in the peel. The present work focuses phytochemical studies for identification of the main groups of existent substances in the species, besides morphologic and histological studies for differentiation among other species of the gender.
\end{abstract}

Keywords: alkaloids, phytochemical; morphohistological.

\section{INTRODUÇÃ̃O}

A Erythrina falcata Benth. é uma árvore da família Fabaceae, subfamília Papilionoideae, conhecida pela sinonímia popular de muchoqueiro, mulungu ou sapatinho-de-judeu, bastante comum na região Sul de Minas Gerais e frequentemente utilizada por populares na cura de doenças do aparelho respiratório, como sedativo e como ansiolítico.

Embora seja também conhecida como Mulungu, a Farmacopéia Brasileira (1929) reconhece como planta oficial para fins industriais na produção de medicamentos ansiolíticos a Erythrina mulungu. Daí a necessidade de se fazer o presente estudo para identificar algumas características fundamentais e assim evitar equívocos quanto aos seus efeitos farmacológicos e até mesmo falsificações entre essa espécie e outras do gênero Erythrina.

O gênero Erythrina contém cerca de quatrocentas espécies, existentes nas regiões quentes da América, África, Ásia e Oceania (Joly, 1971). Os mulungus, como são conhecidos popularmente, caracterizam-se pela presença de alcaloides distribuídos pela planta, porém acumulados particularmente nas sementes e na casca. Contudo, umas espécies têm elevado teor e outras, ao contrário, são muito pobres em alcaloides (Costa, 1982).

O presente estudo faz parte do projeto de levantamento florístico da flora medicinal realizado no seguimento da Mata Atlântica Urbana que constitui o Parque Zoobotânico de Pouso Alegre-MG e foi também motivo de estudo sobre sua caracterização morfohistológica e fitoquímica e apresentado em dissertação de mestrado ao Curso de Pós-Graduação em Ciências Farmacêuticas da Universidade São Francisco, em Bragança Paulista (SP) (Almeida, 2003). Realizou-se, preliminarmente, um estudo morfológico da espécie E. falcata para em seguida dedicar-se aos estudos histológicos e fitoquímicos, de maneira a fornecer subsídios à identificação do teor da droga constituída por cascas e folhas da espécie.

\section{MATERIAL E MÉTODOS}

O material vegetal, Erythrina falcata Benth., Fabaceae, usado no presente estudo foi coletado especificamente no Parque Zoobotânico de Pouso Alegre, onde a planta cresce espontaneamente. A identificação da espécie foi feita por comparação com exsicatas existentes no Herbário Frei Velloso, da Universidade São Francisco-SP e 
também por análise e estudos em literaturas especializadas. As exsicatas foram depositadas no Herbário Frei Velloso, sob registro VELL. 838, da Universidade São Francisco, em Bragança Paulista-SP, e no Herbário da Universidade do Vale do Sapucaí, em Pouso Alegre-MG.

Os estudos morfológicos das folhas, caules, flores e frutos foram feitos à vista desarmada e com auxílio de lupa. Os estudos da histologia interna foram feitos empregando-se material fresco (folhas e cascas) e conservado em solução de etanol $70 \%$. Os cortes histológicos foram obtidos através da microtécnica à mão livre. Os tecidos com impregnação de celulose foram observados com corante hematoxilina e com azul de Astra (Krauss \& Arduin, 1997). Os tecidos lignificados foram estudados através de coloração com safranina e grãos de amido foram observados com solução de iodo. As lâminas foram fotografadas através de fotomicroscópio Nikon ${ }^{\circledR}$.

Os materiais vegetais utilizados para as análises físicas e químicas da droga e na preparação dos extratos fluidos foram colocados em estufa à temperatura de 40$45^{\circ} \mathrm{C}$, para secagem e posteriormente transformados em pó fino através de moinho de facas e martelos de marca Thomas ${ }^{\circledR}$.

As reações gerais para análise e identificação das principais classes de substâncias químicas em plantas foram realizadas conforme Costa (1982) e Domingues (1973). Os testes para a determinação de substâncias solúveis e insolúveis em ácido foram feitos de acordo com as técnicas descritas na Farmacopéia Brasileira (1929). Foi utilizado aparelho Sartorius para determinação de substâncias voláteis e umidade, no qual foi colocada a droga até a temperatura de $105^{\circ} \mathrm{C}$.

Para a preparação do extrato fluido da casca, foi utilizado percolador de aço inoxidável, de acordo com o processo B da Farmacopéia Brasileira (1929), usando o pó da casca. Como líquido extrator foi utilizada uma mistura de etanol e água destilada $2: 1$. O pH do extrato fluido foi determinado através da leitura direta em peagâmetro Digimed, modelo DM 20, à temperatura de $20{ }^{\circ} \mathrm{C}$, em pHgâmetro Orion ${ }^{\circledR}$, cujo resultado final expressa a média aritmética de três determinações (Farmacopéia Brasileira, 1977). Os índices de refração dos extratos fluidos, após diluídos em álcool 2:1, foram determinados em aparelho refratômetro 2 WAJ, o qual foi calibrado com água à temperatura $20{ }^{\circ} \mathrm{C}$. $\mathrm{O}$ índice de refração da água a essa temperatura é de 1,330 .

Para os testes de determinação do grau alcoólico, as amostras foram preparadas à temperatura de $20^{\circ} \mathrm{C}$, após destilar à temperatura de $90^{\circ} \mathrm{C}$. Deixou-se o líquido atingir a temperatura inicial $\left(20^{\circ} \mathrm{C}\right)$ e em seguida determinou-se o teor alcoólico de acordo com a indicação da Farmacopéia Brasileira (1959).

\section{RESULTADOS}

\section{Descrição geral da planta}

A Erythrina falcata Benth., Fabaceae, é uma planta arbórea espinhenta, de porte grande, chegando a 20 $\mathrm{m}$ de altura, e o tronco a $90 \mathrm{~cm}$ de diâmetro, a altura de 1 $\operatorname{DAP}(1,40 \mathrm{~m}$ do solo) (Figura 1). É planta decídua, heliófita, seletiva higrófita, característica de várzeas e início de encosta (Lorenzi, 2000). Floresce durante o mês de junho, prolongando-se até novembro, quando aparecem também as novas folhas. Os frutos, do tipo legume, amadurecem em setembro-novembro, entretanto permanecem sobre a árvore por mais alguns meses.

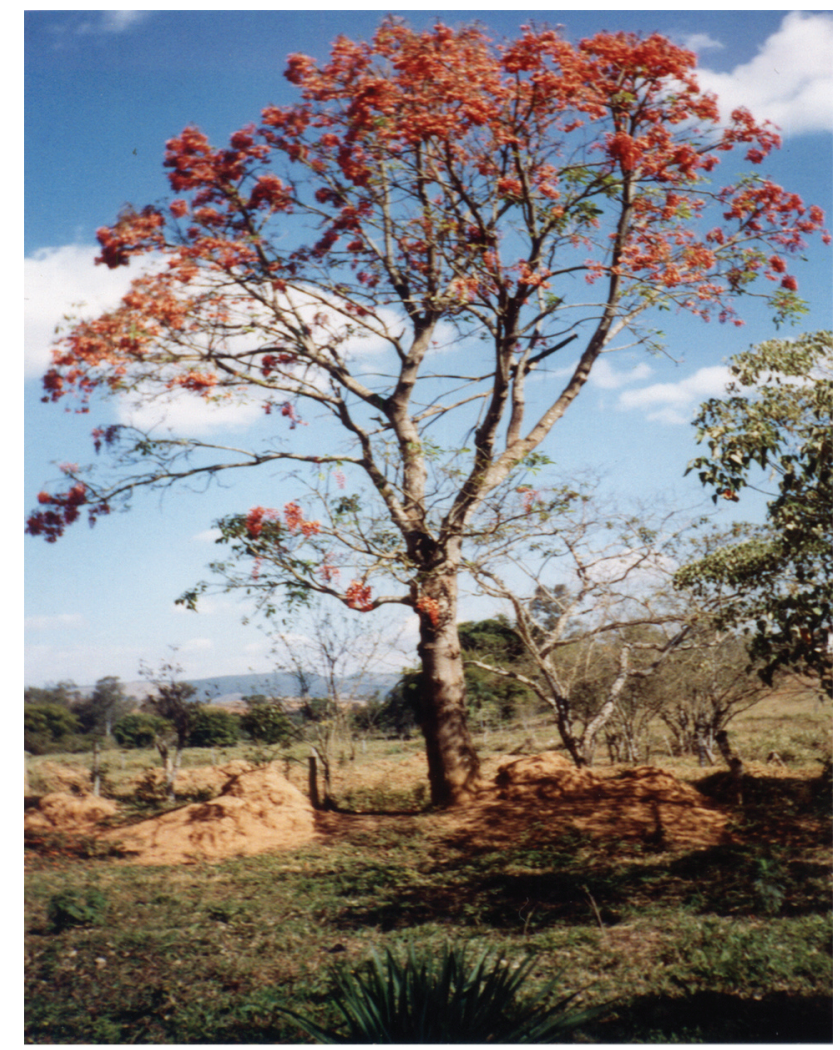

Figura 1. Árvore da Erythrina falcata Benth., Fabaceae, (Espírito Santo do Dourado-MG).

A E. falcata é uma árvore exuberante, vistosa, altamente decorativa, principalmente na época da florada, quando está totalmente destituída de folhas. Ocorre principalmente em Minas Gerais, Mato Grosso do Sul até o Rio Grande do Sul. A madeira é branca, leve, de baixa densidade $\left(0,32 \mathrm{~g} / \mathrm{cm}^{3}\right)$, textura grossa e homogênea, de baixa durabilidade quando exposta ao relento; é empregada para confecção de palitos de fósforo, forros, brinquedos, caixotaria etc. O tronco apresenta coloração cinzenta, suberoso, com muitas fendas verticais. A casca é de consistência muito dura, de difícil corte, já a parte interna apresenta-se porosa, com muitas fibras. As extremidades dos ramos, bem como a planta jovem possuem casca com coloração avermelhada e muitos acúleos.

A casca do caule adulto apresenta acúleos cônicos, com cerca de $1 \mathrm{~cm}$ na base e igual medida nas alturas; observou-se também entre as fendas do súber a 
presença de liquens e musgos. A copa é irregular, medindo em torno de $8 \mathrm{~m}$. A inflorescência do tipo cacho localizase nas extremidades dos ramos. As flores vermelhas, em forma de foice, apresentam o cálice campanulado oblíquo e a corola com estandarte amplo e recurvo.

As folhas compostas são trifolioladas, com pecíolos desprovidos de pêlos, porém com espinhos que se seguem até as nervuras dos folíolos. O folíolo central é maior que os laterais, medindo em torno de $15 \mathrm{~cm}$ de comprimento por $7 \mathrm{~cm}$ de largura; os laterais medem em torno de 10-12 cm de comprimento por 5-6 cm de largura. Quando novos, os folíolos têm aspecto membranáceo e quando adulto coriáceo.

Os folíolos apresentam uma coloração verdeoliva tanto na epiderme superior quanto na inferior e têm uma forma oval-oblonga; quando jovens possuem o ápice mais pontiagudo. Os folíolos apresentam nervura principal que se ramifica em nervuras secundárias tipo peninérvea. O pecíolo é longo e o peciololo é curto; a ráquis é longa e as bordas são lisas.

\section{Descrição microscópica}

\section{Lâmina foliar}

Os cortes transversais da folha ao nível do terço mediano revelaram um mesofilo heterogêneo, com três a quatro camadas de células no parênquima paliçádico. A epiderme superior é revestida por uma cutícula espessa lisa, constituída de células de contorno irregular na forma e tamanho, sendo grande parte delas de forma arredondada. A epiderme inferior é formada de células ligeiramente mamilonadas e desprovida de tricomas, também com cutícula lisa, porém mais espessa, contornando as células (Figura 2).

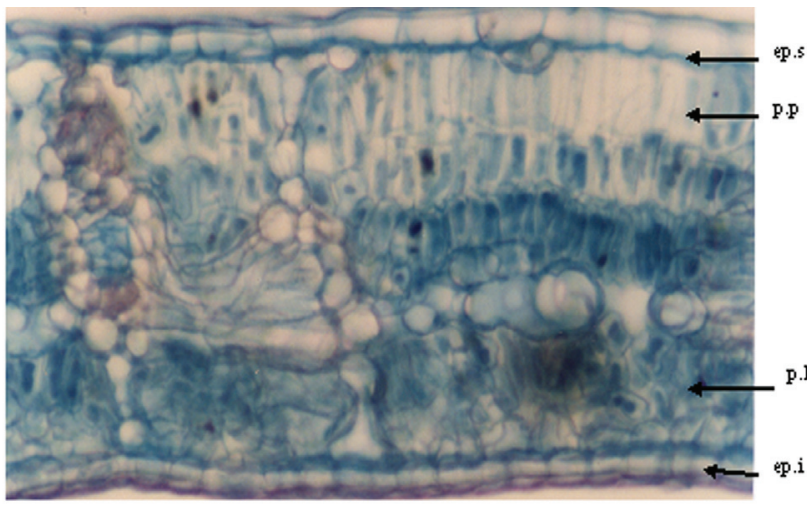

Figura 2. Estrutura microscópica do corte transversal da folha (200x). Corte transversal do limbo: ep.s.-epiderme superior; p.p.parênquima paliçádico; p.l.-parênquima lacunoso; ep.i.-epiderme inferior.

No corte paradérmico, a epiderme inferior apresenta muitos estômatos do tipo paracíticos, anisocíticos e às vezes anomocíticos, os quais ficam ao nível da cutícula e distribuídos pelo limbo foliar. Observou-se, pela transparência, grande quantidade de cristais prismáticos ao longo das nervuras. Não foi observada a presença de pêlos tectores. A nervura principal se ramifica em nervuras secundárias e terciárias. Os pêlos glandulares encontrados principalmente sobre as nervuras são curtos e claviformes, contendo um pedicelo curto e glândula pluricelular. As células epidérmicas são irregularmente poligonais, de parede ligeiramente arqueada. A epiderme superior da folha em corte paradérmico apresenta raros estômatos paracíticos e as células são irregulares na forma e tamanho (Figura 3).

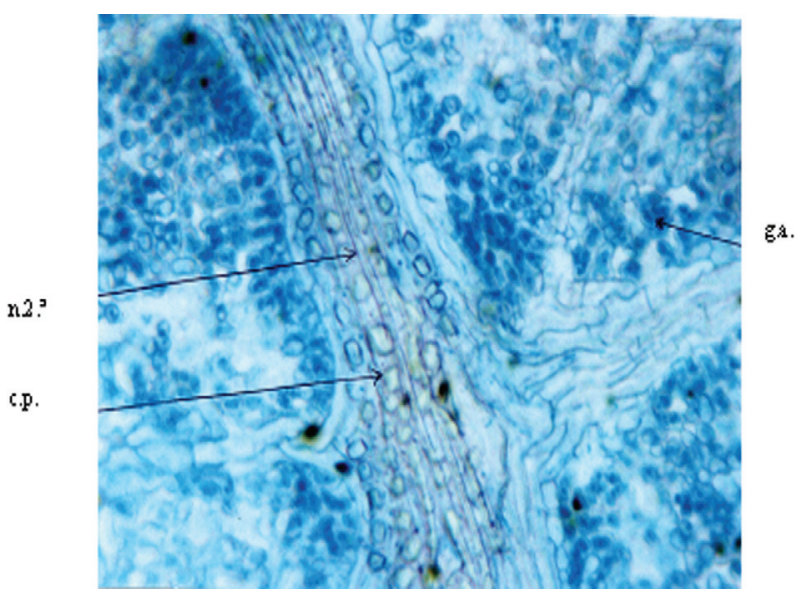

Figura 3. Corte paradérmico da epiderme inferior: em destaque cristais prismáticos $(100 \mathrm{x})$ (g.a.-grãos de amido; c.p. cristais prismáticos; n.2. ${ }^{a}$-nervura secundária).

Pecíolo

Em corte transversal efetuado junto à porção distal ao limbo foliar, o pecíolo apresenta contorno ovalado, sendo ligeiramente côncavo na região voltada para a face adaxial e convexa na correspondente à face abaxial. A epiderme é constituída de células de contorno irregular na forma e tamanho e a cutícula é espessa e não apresenta tricoma. O colênquima, localizado logo abaixo da epiderme, é constituído por duas a quatro camadas celulares com espessamento angular; nota-se frequentemente a presença de pequenos espaços localizados no centro do espessamento colenquimático. O parênquima fundamental é bem desenvolvido, envolvendo treze feixes vasculares colaterais abertos.

O pecíolo em corte transversal apresenta parênquima cortical dividido nitidamente em duas regiões por um periciclo esclerenquimático fibroso, separando para o lado de fora a região cortical e para o lado de dentro os feixes vasculares; no parênquima cortical encontramse frequentemente células gigantes e espaço lacunar. $\mathrm{O}$ câmbio é estreito, formando de duas a três camadas de células achatadas e superpostas. Após o câmbio, encontrase uma faixa larga de xilema com fibras espessadas e vasos geralmente grandes (Figura 4). 
No corte longitudinal do pecíolo, observam-se células gigantes, principalmente na região floemática, e muitos cristais prismáticos. Há ainda presença de feixes de fibras lignificadas e conjuntos de vasos líbero-lenhosos.

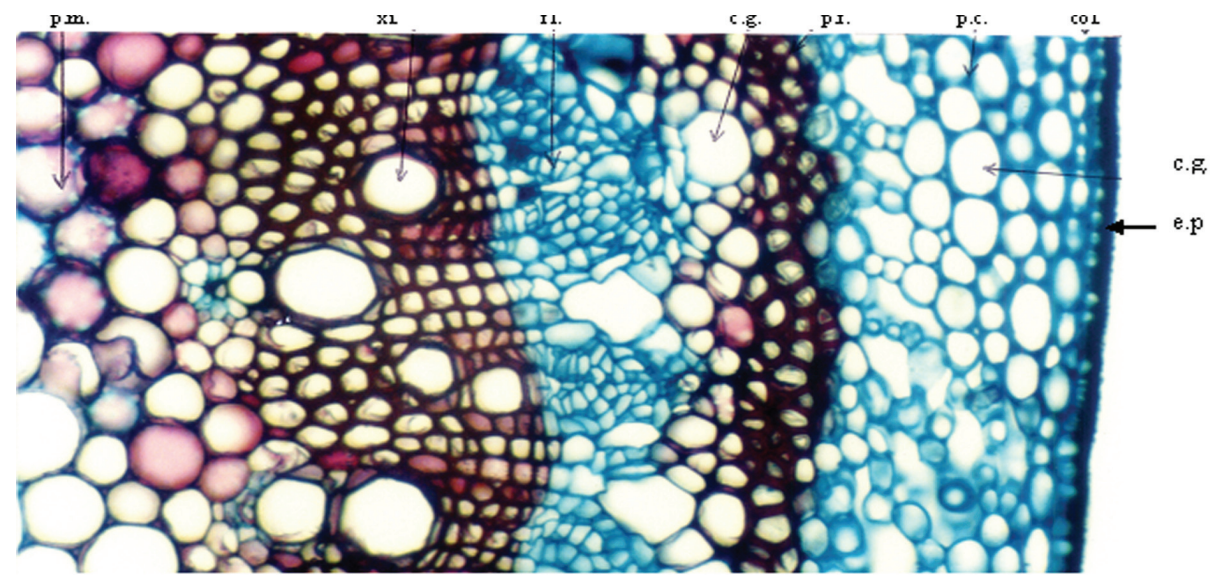

Figura 4. Corte transversal do pecíolo (100x) (xi.-xilema; fl.-floema; p.c.-parênquima cortical; col. -colênquima; ep.-epiderme; p.m.parênquima medular; p.f.-periciclo fibroso; c.g.-célula gigante).

Casca

O corte transversal da casca mostra a estrutura geral, que apresenta conjuntos de fibras lignificadas distribuídas uniformemente ao longo do parênquima. As células do parênquima são irregulares na forma e tamanho, tornando-se achatadas à medida que se aproximam do súber atravessado por raios medulares constituídos de cinco a seis fileiras de células. No parênquima, há a ocorrência de cristais prismáticos em forma de ataúde (Figura 5).

$\mathrm{O}$ corte longitudinal tangencial da casca apresenta em seu conjunto estrutural feixes de fibras, raios medulares e, ao longo de sua estrutura, a presença de cristais prismáticos em bainha cristalífera e o corte longitudinal radial da casca, em sua estrutura geral, apresenta também cristais prismáticos incrustados em suas células parenquimáticas corticais formando bainha cristalífera.

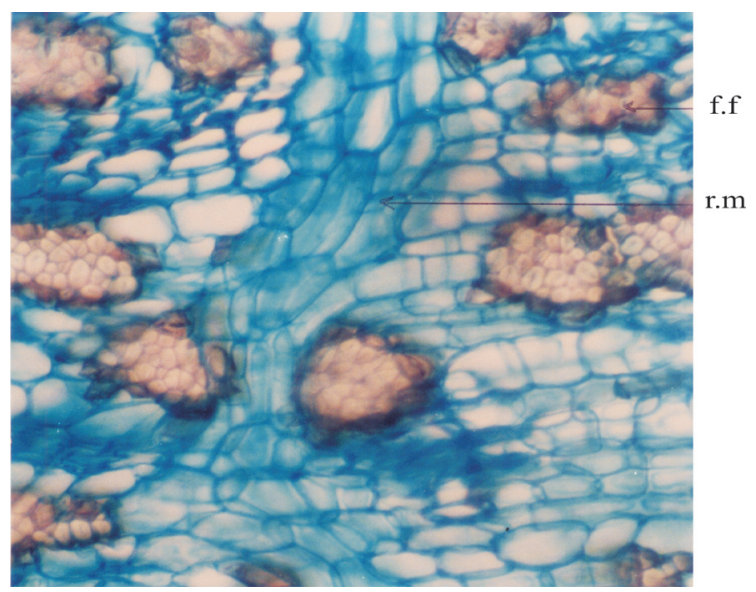

Figura 5. Corte transversal da casca: em destaque feixes de fibras lignificadas (100x); (f.f.-feixe de fibras; r.m.-raio medular).

\section{Estudos fitoquímicos}

De acordo com os testes fitoquímicos realizados, foi constatada a presença das seguintes classes de substâncias: taninos, alcaloides, glicosídeos antraquinônicos e glicosídeos flavonoídicos. Os testes para glicosídeos cardiotônicos e glicosídeos saponínicos deram negativos, conforme pode ser observado na Tabela 1 .

Tabela 1. Resultado dos testes fitoquímicos indicadores da presença das principais classes de substâncias na casca de Erythrina falcata Benth., Fabaceae.

\begin{tabular}{lcc}
\hline \multicolumn{1}{c}{ Substâncias } & Droga & Extrato \\
\hline Taninos & ++ & ++ \\
Alcaloides & + & + \\
Glicosideos cardiotônicos & - & - \\
Glicosideos antraquinônicos & + & + \\
Glicosídeos flavonoídicos & ++ & ++ \\
Glicosídeos saponínicos & - & - \\
\hline
\end{tabular}

+ presentes (reação fraca); ++ presentes (reação média); - ausentes

\section{Constantes fisicas}

A abordagem das constantes físicas, com relação ao $\mathrm{pH}$, densidade, índice de refração e teor alcoólico dos extratos fluidos da $E$. falcata podem ser observados na Tabela 2.

Tabela 2. Resultados dos testes de $\mathrm{pH}$, densidade, índice de refração e de teor alcoólico dos extratos fluidos da Erythrina falcata Benth., Fabaceae, a $20^{\circ} \mathrm{C}$.

\begin{tabular}{|c|c|}
\hline Testes & Resultados \\
\hline pH do extrato fluido & 6,11 \\
\hline Densidade do extrato & 0,9895 \\
\hline Índice de refração & 1,372 \\
\hline Teor alcoólico & $63 \%$ \\
\hline & $\begin{array}{l}\text { Rev. Bras. Farmacogn. } \\
\text { Braz. J. Pharmacogn. } \\
\text { 20(1): Jan./Mar. } 2010\end{array}$ \\
\hline
\end{tabular}


Substâncias voláteis até $105{ }^{\circ} \mathrm{C}$ e cinzas solúveis e insolúveis em ácido

Os resultados obtidos na droga e no extrato de partes aéreas da E. falcata encontram-se nas Tabelas $3 \mathrm{e}$ 4.

Tabela 3. Teor de cinzas solúveis e insolúveis em ácido da casca.

\begin{tabular}{lcc}
\hline \multirow{2}{*}{ Parâmetros } & \multicolumn{2}{c}{ Substâncias voláteis } \\
\cline { 2 - 3 } & Droga $(\mathrm{m} / \mathrm{m})$ & Extrato $(\mathrm{v} / \mathrm{p})$ \\
\hline $\begin{array}{l}\text { Teor de cinzas totais da } \\
\text { casca em \% }\end{array}$ & 8,63 & 1,94 \\
$\begin{array}{l}\text { Teor de cinzas insolúveis } \\
\text { em ácido da casca em \% }\end{array}$ & 0,93 & 0,46 \\
\hline
\end{tabular}

Tabela 4. Percentagens de substâncias voláteis a $105^{\circ} \mathrm{C}$.

\begin{tabular}{llc}
\hline \multicolumn{1}{c}{ Parâmetros } & \multicolumn{2}{c}{ Média das leituras $(\%)$} \\
\cline { 2 - 3 } & $\begin{array}{c}\text { Resíduos } \\
(\mathrm{p} / \mathrm{p})\end{array}$ & $\begin{array}{c}\text { Voláteis } \\
(\mathrm{p} / \mathrm{p})\end{array}$ \\
\hline $\begin{array}{l}\text { Substâncias voláteis nas } \\
\text { folhas frescas }\end{array}$ & 58,54 & 41,46 \\
$\begin{array}{l}\text { Substâncias voláteis a } 105^{\circ} \mathrm{C} \\
\text { e resíduos secos do extrato } \\
\text { fluido da casca }\end{array}$ & 78,49 & 21,51 \\
$\begin{array}{l}\text { Substâncias voláteis a } 105 \\
{ }^{\circ} \mathrm{C} \text { e resíduos secos da casca } \\
\text { pulverizada }\end{array}$ & 10,03 & \\
\hline
\end{tabular}

\section{DISCUSSÃO}

Comooobjetivodeste trabalhoéfornecersubsídios para um melhor controle de qualidade de fitoterápicos, para indústrias farmacêuticas ou farmácias de manipulação, procurou-se identificar e caracterizar a Erythrina falcata Benth., Fabaceae, uma vez que existem várias espécies do gênero Erythrina, todas elas apresentando alcaloides, em maior ou menor quantidade. Esses alcaloides podem trazer consequências graves à saúde, como intoxicação, ação ansiolítica e hipnótica, devido à variação quantitativa e qualitativa de princípio ativo que pode ocorrer.

Morfologicamente, a E. falcata apresenta características macroscópicas bem distintas. Tem um porte maior (20 m), copa arredondada, de aspecto irregular, tronco grosso de casca acinzentada, com fendas longitudinais que são interrompidas por fendas horizontais; as folhas trifolioladas, de aspecto ovalado, com ápice acuminado e de cor verde-oliva e aspecto coriácea; os ramos mais novos apresentam acúleos e são de coloração avermelhada; a inflorescência é de cor vermelho-coral, do tipo racemo, localizada na extremidade dos ramos.

$\mathrm{Na}$ microscopia das folhas, a E. falcata revela não possuir pêlos tectores e possuir uma quantidade menor de estômatos na epiderme superior e grande quantidade de cristais prismáticos em forma de ataúde.

Nos cortes transversais da folha, a E. falcata revela nervura principal em aspecto ovalado, com uma protuberância na face adaxial, um conjunto de 10-13 feixes vasculares colaterais abertos; a epiderme é desprovida de tricomas e é constituída de células de contorno irregular, grande parte delas de forma arredondada simulando a forma de mamilo e a cutícula é espessa.

Os cortes histológicos das aletas do limbo mostram na $E$. falcata um mesofilo heterogêneo com três camadas de células no parênquima paliçádico, epiderme espessa e ausência de tricomas.

Em relação aos cortes histológicos das cascas, observou-se que a $E$. falcata apresenta grande quantidade de cristais prismáticos em forma de ataúde, muitos feixes de fibras; os cristais prismáticos concentram-se em volta das fibras, em bainhas cristalíferas localizadas no parênquima cortical secundário, podendo ser observados também ceratênquimas tanto em corte longitudinal radial como no corte tangencial.

Em relação às principais classes de substâncias, observaram-se que estão presentes alcaloides, taninos, bem como os glicosídeos antraquinônicos e flavonoídicos, na espécie estudada (Tabela 1). Para os testes indicativos de flavonoides, usando-se os reativos de Shinoda, cloreto de alumínio, cloreto férrico, hidróxido de sódio, cloreto de antimônio e oxalato-bórico, verificou-se a ocorrência de pequena quantidade de flavonoides. Com relação à presença de taninos, os testes deram positivos para todos os reativos e ensaios. Para os testes de saponina e de glicosídeos cardiotônicos, verificou-se que as reações foram negativas. Já os testes indicativos de glicosídeos antraquinônicos, usando-se o reativo de Bornträeger, deram positivo, com presença de geninas antraquinônicas.

\section{CONCLUSÃO}

O trabalho de pesquisa realizado com a espécie Erythrina falcata Benth., Fabaceae, visou identificar e caracterizar os aspectos morfológicos e histológicos e também para definir um padrão de qualidade que possa evitar fraudes quanto à sua indicação terapêutica, o que nos permitiu tirar algumas conclusões que nos forneceram subsídios para evitar equívocos quanto ao uso farmacológico dessas plantas.

As características microscópicas, importantes na morfodiagnose da droga constituída de folhas, não deixam dúvida quando do estudo do mesofilo, da epiderme inferior e superior, tricoma, estômatos e características do pecíolo. Quanto à análise dos testes farmacognósticos, observouse que estão presentes várias classes de princípios ativos, tais como alcaloides, flavonoides, taninos, glicosídeos antraquinônicos e pequena quantidade de óleo essencial e saponinas.

Desse modo, o controle de qualidade dos fitoterápicos não deve se restringir apenas à análise do 
produto acabado, mas deve compreender a análise da matéria-prima, desde a sua colheita, preparo da droga, identificação, extração, beneficiamento, até a forma farmacêutica final. Isso significa que para se fazer uma análise de fitoterápicos, deve-se identificar a droga vegetal, através de estudo morfohistológico e, posteriormente, fazer testes das constantes físicas e triagem química, para que não ocorram trocas entre as espécies e falsificação com outras espécies desconhecidas.

Portanto, o que se chegou à conclusão é que não é aconselhável o uso de cascas dessa espécie de Erythrina por populares sem a consulta de um especialista, pois o consumo indiscriminado pode trazer consequências graves. $\mathrm{O}$ seu uso farmacológico, portanto, deve ficar restrito às indústrias e farmácias de manipulação para a produção de medicamentos, com um rigoroso controle de qualidade.

\section{REFERÊNCIAS}

AlmeidaEE2003. Identificaçãoe caracterizaçãofarmacognóstica de três espécies de mulungus do gênero Erythrina visando ao controle de qualidade. Bragança Paulista, 130 p. Dissertação de Mestrado, Programa de PósGraduação em Ciências Farmacêuticas, Universidade São Francisco.

Costa AF 1982. Farmacognosia. Lisboa: Calouste Gulbenkian.

Domingues XA 1973. Métodos de investigação fitoquímica. México: Limusa.

Farmacopéia dos Estados Unidos do Brasil 1929. São Paulo: Cia. Ed. Nacional. p. 385-666.

Farmacopéia dos Estados Unidos do Brasil 1959. 2. ed. São Paulo: Siqueira. p. 959.

Farmacopéia dos Estados Unidos do Brasil 1977. 3. ed. São Paulo: Cia. Ed. Nacional. p. 915.

Joly AB 1971. Botânica: introdução à taxonomia vegetal. São Paulo: Cia Ed. Nacional.

Krauss JE, Arduin M 1997. Manual básico de métodos em morfologia vegetal. Rio de Janeiro: EUDR.

Lorenzi H 2000. Árvores brasileiras: manual de identificação e cultivo de plantas arbóreas nativas do Brasil. Nova Odessa: Plantarum. 